\title{
March for women
}

\author{
March is Women's History Month. This issue of Nature Immunology celebrates the contributions of women in \\ immunology by presenting specially commissioned content from women across the globe.
}

$\mathrm{M}$ arch 8 is celebrated annually throughout the world as International Women's Day. In 2016-2017, the United Nations issued declarations to promote gender equality and proclaimed a goal of "Planet 50-50 by 2030 ." In the United States, which in 2020 is celebrating the centennial of the ratification of the Nineteenth Amendment to the US Constitution, guaranteeing women's right to vote, the entire month of March is dedicated as Women's History Month. As we embark on a new decade, heeding the United Nation's stated goal of gender equality within the next ten years, we thought it fitting to celebrate Women in Immunology in our March issue. A special collection can be found at https:// www.nature.com/collections/women-inimmunology.

This Focus issue features a new commissioned content type for Nature Immunology, the World View. Five female immunologists, representing four continents and a range of career stages, offer reflections and advice on navigating career steps and negotiating the shoals of a still maledominated research environment. All are passionate about their careers and their love of immunology. Xiaoyu $\mathrm{Hu}$ (Beijing, China) recounts her experiences as a female faculty member in both the East (Tsinghua University) and the West (Weill Cornell Medical College, New York). She speaks with humor about stereotypes she has encountered in both countries, yet remains undaunted. Cherié Butts (Cambridge, Massachusetts, USA) describes her journey in biomedical research from her student days in academia, to being a governmentemployed regulatory scientist at the US Food \& Drug Administration, to a strategic team leader at the pharmaceutical company Biogen. Each new role looked at common research problems with different viewpoints and presented new opportunities, hence vastly expanding the horizons that she first envisioned on entering her career. Marion Pepper (Seattle) issues a challenge to male immunologists (and all male scientists), noting that they too have a role to play in achieving gender equality in the research enterprise. First, be aware of the implicit bias that exists; then, do something about it! Treat your female colleagues as you do your male colleagues. Hedda Wardemann (Heidelberg, Germany) describes her serendipitous career journey as a postdoc at Rockefeller University in New York and her return to Germany as a faculty member, first in Berlin, then as a tenured faculty member in Heidelberg. Along the way, life happened - two daughters arrived, which complicated career choices (as it does for most parents). Fabienne Mackay (Melbourne, Australia) speaks on her academic executive role as head of Biomedical Sciences at the University of Melbourne. She articulates the challenges that face institutional administrators in making personnel decisions about recruiting, hiring and promotions. She then describes ways of supporting talented researchers, regardless of their gender.

In a Comment, Ann Ager (Cardiff, UK) describes the public advisory role that she serves, in addition to heading a laboratory and her academic responsibilities. Ann represents the British Society for Immunology (BSI) as an immunology advocate who can offer expert advice to members of Parliament and other governmental policy makers tasked with formulating national health and science policies. She is also a spokesperson for the BSI in the more global setting of the International Union of Immunological Societies. Such advisory roles involve the input of multiple committees within the BSI and other stakeholders within the biosciences research community, hence one is speaking for the society, not merely espousing a personal viewpoint. She encourages others to get involved in their local immunology societies and put their hat into the ring by standing for committee election.

A Perspective on the achievements of and challenges for women in immunology is offered by a quartet of female intramural researchers at the National Institutes of Health (Bethesda, Maryland, USA). Pierce et al. discuss the question of why, despite the numerous contributions of women to immunology and other areas of science, the career trajectories of women, on average, do not match those of men, despite nearly equal representation at the doctoral and postdoctoral levels. They propose steps to rectify this global imbalance at senior leadership positions that include changes in resource allocation, fostering mentorship and advocacy programs, and, as mentioned above, challenging entrenched stereotypes. The last point includes a reevaluation of the traditional metrics by which institutional committees determine promotion and tenure decisions. Most important, though, is the need to provide supportive environments that recognize and value the distinct strengths that women and other underrepresented groups offer to academic and research institutions. Intertwined throughout this piece are examples of the progress seen when such changes are implemented by NIH intramural research programs.

The stories shared in this Focus represent only a snippet of the contributions that women have made to immunology. To the young women who are just embarking on their own research journeys, we hope these stories are inspiring. Top-tier journals can, and must, be advocates for inclusive programs aimed at promoting the careers of female researchers. We recognize that journals also have a role to play in reducing disparities in the manuscript peer-review process by increasing the number of female referees and providing more visibility via solicited News \& Views, Comments and other commissioned content from rising stars, male and female. More on that later. In the meantime, march on.

Published online: 24 February 2020 https://doi.org/10.1038/s41590-020-0627-3 